\title{
Location accuracy of long distance VLF lightning location network
}

\author{
C. J. Rodger ${ }^{1}$, J. B. Brundell ${ }^{2}$, R. L. Dowden ${ }^{2}$, and N. R. Thomson ${ }^{1}$ \\ ${ }^{1}$ Department of Physics, University of Otago, Dunedin, New Zealand \\ ${ }^{2}$ LFEM Research Ltd., 161 Pine Hill Road, Dunedin, New Zealand
}

Received: 19 August 2003 - Accepted: 12 November 2003 - Published: 19 March 2004

\begin{abstract}
An experimental VLF WorldWide Lightning Location (WWLL) network is being developed to provide realtime locations of cloud to ground lightning discharges occurring throughout the globe. This network has expanded from a limited number of stations in the Western Pacific to its current state of 11 stations, in most longitude sectors, with additional stations planned in the near future. As part of the initial testing phase of the WWLL the network has operated in a simple mode, sending the station trigger times into a central processing point rather than using the sferic Time of Group Arrival (TOGA). During this initial stage, a significant quantity of lightning location data has been collected, some of which is being applied to research questions. In this paper the operation of the WWLL network is described, and the location accuracy of the pre-TOGA WWLL network is characterised. This is performed by contrasting commercial lightning location data from an Australian network, Kattron, over 2 days in January 2002, with 4 WWLL stations covering the same region. It was found that there were 426 matched lightning events, corresponding to lightning discharges with large lightning return stroke peak currents (mean absolute peak current of $\sim 26 \mathrm{kA}$ compared with $\sim 12 \mathrm{kA}$ for all Kattron events). By considering the random errors in the difference locations between the matching lightning events, an appropriate Gaussian timing error for the WWLL network of receiving stations is determined, and hence an estimate for the global location errors for the existing 11-station network is found. The "worst-case" global location error for the existing network ranges spatially from $7.5-100 \mathrm{~km}$, with the global median being $15 \mathrm{~km}$, and the global mean $30 \mathrm{~km}$. When the TOGA method is implemented, the station timing errors will decrease, allowing for an increase in the location accuracies. Hence, the location accuracy estimates determined in this paper will be very conservative for the future WWLL network employing the TOGA technique.
\end{abstract}

Key words. Meteorology and atmospheric dynamics (lightning, atmospheric electricity, instruments and techniques)

Correspondence to: C. J. Rodger

(crodger@physics.otago.ac.nz)

\section{Introduction}

Lightning discharges are powerful impulsive sources of electromagnetic energy over a wide bandwidth (up to optical), with significant radiated electromagnetic power from a few hertz to several hundred megahertz (Magono, 1980), and the bulk of the energy radiated in the frequency bands $<30 \mathrm{kHz}$ (Pierce, 1977). Passive lightning location methods rely upon the energy released by the lightning discharge, acoustically (thunder), optically (lightning), and electromagnetically (Uman, 1987). Today, commercial lightning location networks are in operation in many regions of the world, using multiple stations to locate the source of lightning electromagnetic radiation pulses. The economic advantages that many groups obtain from accurate and virtually instantaneous lightning location data, results in this data being in high demand from many industries, such as electricity generators and distributors, aviation, forestry, sporting groups, insurance companies and weather forecasters (Cummins et al., 1998b). In addition to these groups, there is also strong scientific interest in the application of lightning data to a wide range of research topics, including lightning and related thunderstorm processes (Lyons et al., 1998), high altitude discharges (Rodger, 1999), global warming (Williams, 1992, Schlegel et al., 2001), regional meteorological processes (Hamid et al., 2001), production of important trace chemicals (Jourdain and Hauglustaine, 2001), determination of ionospheric parameters (Cummer et al., 1998), and losses from the Van Allen radiation belts (Rodger and Clilverd, 2002).

Multi-station lightning location systems generally consist of a number of spatially separated receiver stations positioned on the surface of the Earth. The information from each station is, on its own, insufficient to enable the location of the discharge to be determined. However, when the information from some or all of the stations is combined together at a central site, the location of the discharge can be determined. An example is the United States National Lightning Detection Network (NLDN), which in 1996 used 106 sensors located over the continental United States to achieve a typical accuracy of $0.5 \mathrm{~km}$ (Cummins et al., 1998). Many commercial 
lightning detection networks require such high location accuracies to allow electrical power transmission companies to quickly locate lightning produced line faults or to assist insurance inspectors in checking claims. Such networks rely upon the first few microseconds of the lightning pulse received in the MF band (0.3-3 MHz), thus avoiding the sky wave (that which reflects from the ionosphere), and processing only the ground wave (which has high attenuation at the high frequencies used). Thus, NLDN requires $>100$ ground stations to cover the contiguous US $\left(\sim 10^{7} \mathrm{~km}^{2}\right)$, corresponding to a ground station density of $\sim 10 \mathrm{Mm}^{-2}$. This high density of ground stations is not commercially feasible for large areas of low population density or over the oceans.

Two approaches have been put forward to decrease the relatively high cost and complexity of multi-station MF lightning detection networks. Techniques have been developed to allow a single-station lightning location (which might be more appropriate for an aircraft or vessel), often by combining a direction finding method with a procedure by which the distance of the lightning discharge can be estimated (see the review in Rafalsky et al. (1995)). One such technique was validated by comparing the single station determined positions with those reported by a commercial lightning detection network (Brundell et al., 2002). Making use of 85 sferics observed at near Darwin, Australia, it was found that the $68 \%$ accuracy limits for the "Kharkov" single station lightning location method (developed by Rafalsky et al., 1995) were $\sim 4^{\circ}$ in bearing and $\sim 73 \mathrm{~km}$ in range (Brundell et al., 2002). In this paper we will concentrate upon an another approach which makes use of the considerable sferic power present in the VLF band $(3-30 \mathrm{kHz})$, such that very-long range remote sensing is possible; these VLF signals can be received thousands of kilometres from the source (Crombie, 1964)), as the electromagnetic energy propagates with low attenuation inside the waveguide formed by the conducting Earth and the lower boundary of the ionosphere, termed the Earth-Ionosphere Waveguide (EIWG). Propagation over such ranges in the EIWG disperses the initial sharp pulse of the lightning stroke into a wave train lasting a millisecond or more. The amplitude of the received sferic wave train rises slowly (over a few hundred microseconds) from the noise floor, so there is no sharp onset and no sharply defined Time of Arrival (TOA) at the receiving station. The use of differing sferic frequency ranges in multi-station lightning location networks has been discussed by Cummins and Murphy (2000) and Dowden et al. (2002).

Recognising the low-capital requirements of lightninglocation networks operating in the VLF-band, a 7-station sferic observational network has been operated by the UK Met Office from the United Kingdom (5 stations), Gibraltar, and Cyprus, and provides operational lightning observations over much of Europe. This measures the Arrival Time Differences (ATD) between sferics received at two sites by taking the cross-correlations of the full VLF waveforms that have been transmitted back to a central processing station (Lee, 1986a, 1986b, 1989). Through a minimization process an estimate of the discharge location is found from a minimum of 3 ATD measurements, i.e. from a sferic observed at a minimum of 4 stations. Building on the ATD technique developed for the UK Met Office network, experimental VLF ATD networks have been operated in the United States (Morales et al., 2003), and Europe (Chronis and Anagnostou, 2003). In the earlier version of the UK Met Office network, the ATD system used atomic clocks for its time stamp and phone lines to transmit the waveform data. The more recent experimental networks have relied upon Global Positioning System (GPS) technology for timing and broadband internet connections to transmit the lightning VLF waveforms to the central station.

The use of the waveform cross-correlation to determine the ATDs is required to compensate for the dispersion of the lightning generated sferic as it propagates to the receiving stations inside the EIWG. An alternative approach is to determine the Time of Group Arrival (TOGA) of the sferic wave-train received at each station, determined relative to the GPS at each site from the progression of phase versus frequency using the whole waveform (Dowden et al., 2002). The TOGA method avoids the requirement of transmitting the entire VLF waveform back to a central station for processing; the lightning locations can be determined from differences in the TOGA times using the same residual minimization methods employed in the ATD technique (Lee, 1986a). This decreases the internet costs associated with long-range lightning location data-transfers, and means that "normal" UDP (User Datagram Protocol) internet transmission will provide an acceptable real-time lightning location $(<10 \mathrm{~s})$ without the requirement of special broadband connections.

Low-Frequency Electromagnetic Research Ltd. is currently creating an experimental VLF World Wide Lightning Location (WWLL) network through collaborations with research institutions across the globe. As part of the initial testing phase, the stations have operated in a simple mode, sending the trigger time, relative to GPS, back to the central station (in Dunedin, New Zealand) for processing to produce a lightning location. Triggering occurs when the difference between successive samples exceeds the threshold, $V_{t h}$. The trigger time is the time of the second digitised sample. Recently (1 August 2003), the processing algorithm was modified to determine the sferic TOGA at each station, which is expected to lead to improved network performance. However, during the initial experimental stage of the WWLL (2001-2003), a significant quantity of lightning location data has been collected. Some of this data is being applied to research questions, for example, red sprite observations from Taiwan (Su et al., 2003), the ill-fated STS107 mission (Yair, 2003), and the sparking of bushfires in Australia. In this paper we characterise the location accuracy of the pre-TOGA algorithm WWLL network, particularly the early stages of the network structure where stations were limited to the Western Pacific (pre-March 2003), by comparing the WWLL locations with lightning location data which was purchased from a commercial Australian lightning location network, Kattron. This represents the first experimental data from the WWLL network. We go on to estimate the location 


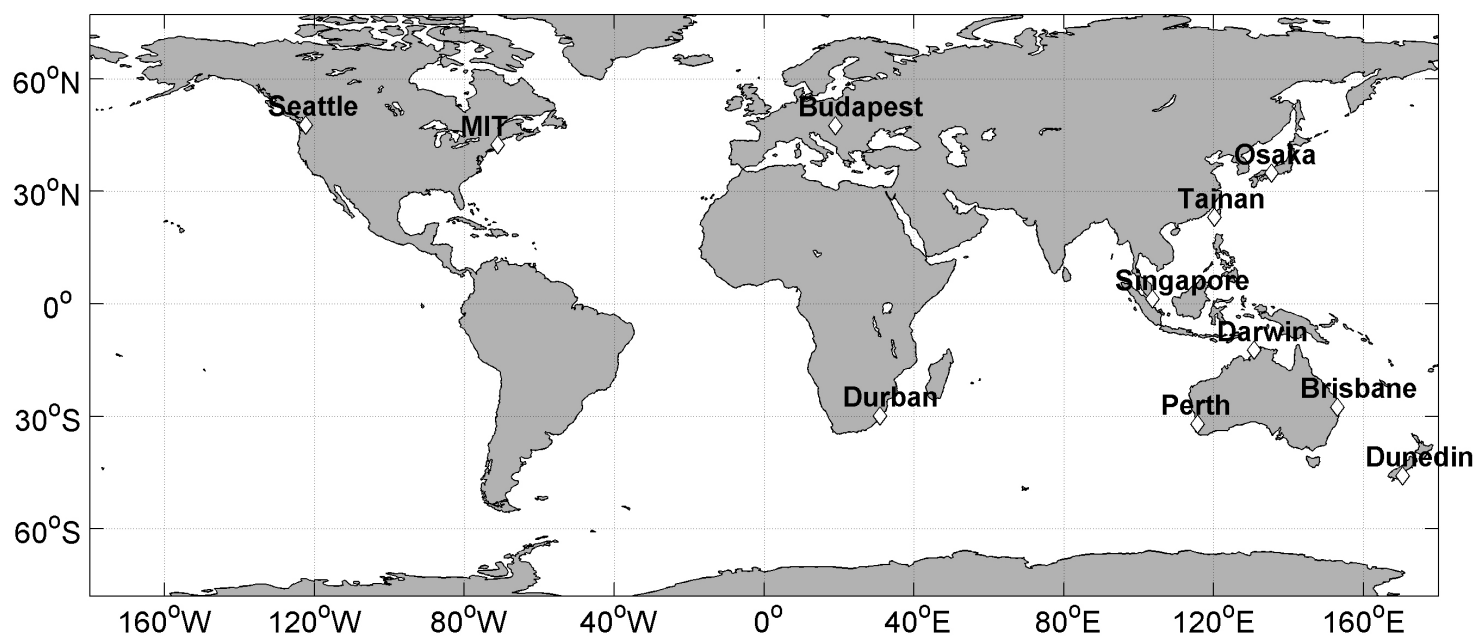

Fig. 1. Locations of the 11 VLF receiving stations (shown as diamonds) currently returning lightning trigger times to the central processing point in Dunedin, New Zealand.

Table 1. Locations and hosts of the 11 VLF receiving stations currently operating in the VLF WorldWide Lightning Location Network.

\begin{tabular}{lrrl}
\hline Location & Latitude $(\mathrm{N})$ & Longitude $(\mathrm{E})$ & Host \\
\hline Dunedin & -45.8639 & 170.514 & University of Otago \\
Darwin & -12.3718 & 130.868 & Northern Territory University \\
Perth & -32.0663 & 115.836 & Murdoch University \\
Brisbane & -27.5534 & 153.052 & Griffith University \\
\hline Osaka & 34.8232 & 135.523 & Osaka University \\
Singapore & 1.2971 & 103.779 & National University of Singapore \\
Tainan & 22.996 & 120.219 & National Cheng Kung University \\
Budapest & 47.4748 & 19.062 & Etvs University \\
Seattle & 47.654 & -122.309 & University of Washington \\
MIT & 42.3604 & -71.0894 & Massachusetts Institute of Technology \\
Durban & -29.8711 & 30.9764 & University of Natal \\
\hline
\end{tabular}

accuracy of a global network of WWLL receiving stations as currently deployed and recording data. The basic operation of the WWLL receiving stations, the location finding process, network operation, and TOGA calculation are described in Dowden et al. (2002).

\section{WWLL network description}

\subsection{VLF receiving stations}

All of the current VLF WWLL receiving stations are located in built-up areas unsuitable for use of magnetic loop antennas at VLF because power line interference will dominate over the magnetic field of the sferic. However, this is not true for the sferic electric field because at VLF even adequate conductors, such as ferroconcrete buildings, remain at ground potential and shield man-made electric fields generated within them. Consequently, the WWLL receiving stations require only a short $(1.5 \mathrm{~m})$ whip antenna on a tall building to measure the vertical electric field of the sferic TM waveguide mode. This is fed into the soundcard of the processing computer and combined with precise GPS timing to determine the sferic trigger time, and hence an estimate of the lightning discharge location (as outlined in Dowden et al. (2002)). At the time of writing, the WWLL network consists of 11 receiving stations, shown as diamonds in Fig. 1 and listed Table 1, and a central processing station in Dunedin, New Zealand. The 7 stations in the Western Pacific represent the initial operational network, with the additional 4 stations included in the data processing around March 2003. There are currently plans for further stations in South America, the central Pacific, India, the southern United States and the Middle East. The lightning receiving station at each research institute is provided by the project but each host meets local costs (mainly Internet). In return, the hosts are provided with historic lightning data from the worldwide network. As seen from the map above, the stations are far from being uniformly spaced, and the network 


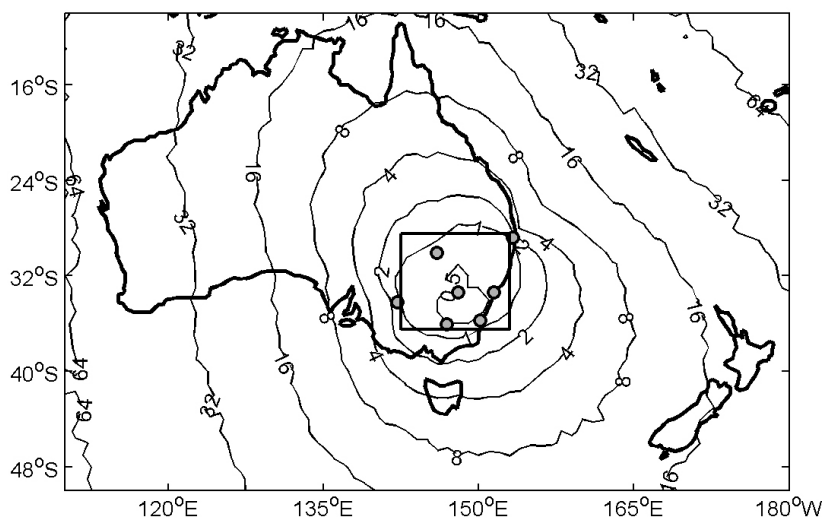

Fig. 2. The estimated location accuracy of the Kattron LPATS TOA lightning location network. The contours have units of kilometres.

P.I. (R. L. Dowden) would be pleased to hear from anyone who could help bridge the larger gaps. Our initial analysis will focus upon the 4 stations in Australia and New Zealand (above the line in Table 1) which allow for the best comparison with commercial lightning location data as outlined in Sect. 6 below.

\subsection{Selection of a common lightning stroke}

The very long range of VLF propagation makes the task difficult of sorting the TOGA values returned from each station (expected to reach $\sim 20$ ) into sets due to a common lightning stroke. This is because the average rate of sferics received at any one station is about $30 \mathrm{~s}^{-1}$, corresponding to an average time between sferics of about $33 \mathrm{~ms}$, which is also the time for propagation over $10 \mathrm{Mm}$. To make matters worse, the sferic rate varies greatly about this average. We currently adjust the detection threshold, $V_{t h}$, to reduce detection of very distant, and so generally weaker, sferics. In most cases, the station which first detects a given lightning stroke (i.e. that with the earliest trigger time) will be the station nearest to the discharge point. This earliest trigger time will be followed by a series of later trigger times returned for processing by other stations. A group of $N$ Time Of Arrivals (1 TOA from each of $N$ stations) can all be due to a single stroke if all non-redundant TOA differences are less than the travel time from one station to another; the interstation travel times are pre-calculated using a representative VLF group velocity and stored as a $16 \times 16$ matrix termed "MAXTOA". If this test is passed, it indicates that all the TOA times may be due to a common stroke. While this test provides a necessary condition for commonality, it is not sufficient to determine that all the observed TOAs are due to a common discharge. Nonetheless, this rather simple test appears to adequately combine the received station TOAs into lightning locations. On average, around one-third to one-half of the TOAs sent by the network are able to be combined to produce locations, although a significantly lower percentage of these locations (around one-third) have small residual values, suggesting good quality lightning locations. The residual is an indication of the error remaining after the minimization processes has produced a location (e.g. Lee, 1986a). It may be that lowering $V_{t h}$ (or allowing more triggers, as explained in Sect. 2.3) to improve detection rates, and the inclusion of additional stations will necessitate the use of a more complex algorithm to select common sferics from a stroke, along the lines proposed previously (Dowden and Rodger, 2002).

\subsection{Limitation of maximum station triggering rate}

During the testing phase of the Western Pacific network, it was found that under certain conditions one of the receiving stations may trigger at an unrealistically high rate (thousands per second), flooding the central processing station with bad TOA values, such that no sensible lightning location estimates are possible. This can happen when an active thunderstorm moves very close to a WWLL station and may be caused by the high electric fields near the thunderstorm. This issue is not unique to our WWLL stations, and also occurs for the MF receiving stations commonly deployed in commercial networks (personal communication, Max Thomas, GPATS, Australia). Such runaway stations can "saturate" the central processing station, while also generating Internet charges with no returns. For these reasons since February 2003, the station triggering algorithm incorporates an automatic threshold control which limits the maximum number of triggers a station may return to the central station each second by slowly increasing the trigger threshold over several minutes. The maximum trigger rate is user-defined but is currently set so that the long-term average triggering rate will be 5 per second. Before the inclusion of the automatic threshold control, high fixed $V_{t h}$ detection threshold values were used to avoid network saturation.

\section{Modelling location accuracies of multi-station net- works}

Whilst there is no substitute for "ground truth" in confirming the accuracy of a lightning location network, the location accuracy of a lightning location network can be estimated through computer simulation. Timing errors are simulated by calculating the ATD (or TOA difference) values that an error free system would measure for a lightning discharge occurring at a given position, and corrupting the ATD/TOA difference values with a random error, from an appropriate distribution of errors, to simulate the measurement process. On this basis a location offset can be determined, and thus provide a measurement error. We employ a "Monte Carlo" style simulation to obtain an estimate of the location accuracy for a given network. This is undertaken at each position of interest by determining the location errors for many (simulated) lightning discharges from which the standard deviation of the distribution of errors is recorded as an estimate of the location accuracy of the network at that location. The above method has been implemented, assuming that the errors in the location network may be modelled as Gaussian 
with a user-specified standard deviation. The software has been checked against previous Monte Carlo estimates of the location accuracy of the UK Met Office ATD network (Fig. 1 of Lee (1986b)) and found to agree very well.

The computer simulation of the location accuracy of lightning location networks is employed below to contrast a commercial lightning network with the VLF WWLL data.

\section{Kattron lightning location data}

Kattron, an Australian based company, operates a commercial TOA (Time of Arrival) lightning location network, using a network of Lightning Positioning and Tracking System (LPATS) TOA receivers. The LPATS receivers were supplied by Global Atmospherics Inc., and are similar to those used as part of the NLDN (Cummins et al., 1998a). In 2002 the Kattron network was made up of 7 LPATS receivers, positioned to achieve sub-kilometre location accuracy and high detection efficiencies over most of the high population density regions in Australia (primarily the south-east of the country). The estimated location accuracy for the 7 LPATS TOA sensor Kattron network (grey circles) are shown in Fig 2, calculated through the process outlined in Sect. 3. In this calculation we have assumed a Gaussian timing error of $2.1 \mu \mathrm{s}$, assuming the station-to-station TOA errors to be independent, along with a standard deviation of $1.5 \mu \mathrm{s}$ TOA error for each station, suggested as suitable for an LPATS TOA network (Cummins et al., 1998a). An indication of the detection efficiency of the 2002 Kattron network configuration has been presented for an earlier 6-receiver Kattron configuration (Fig. 2 of Brundell et al., 2002).

Lightning location data sets from the Kattron network were purchased for two days, 23-24 January 2003. The data included all the lightning strokes located by Kattron and, therefore, included some events far from the network itself (i.e. Papua New Guinea). In order to compare the Kattron and WWLL locations, we have limited the Kattron data to that region inside which the Kattron rms location accuracy is $\sim 1 \mathrm{~km}$ or better, as shown by the black square in Fig. 2. Beyond this region the Kattron location uncertainties rapidly increase, becoming significantly larger than that of the WWLL, as shown below. Inside the selected region the Kattron data is significantly more accurate than the expected accuracy of the WWLL network, and hence can provide an estimate of the WWLL location accuracy. On the basis of the detection efficiencies for the 1996 Kattron configuration, we estimate that $>80 \%$ of CG strokes occurring inside the selected region will be detected by Kattron (Fig. 2 of Brundell et al., 2002).

\section{Results}

\subsection{Coincident lightning}

In order to make comparisons between the location estimates for lightning discharges by the Kattron network and WWLL network data, WWLL events were selected which

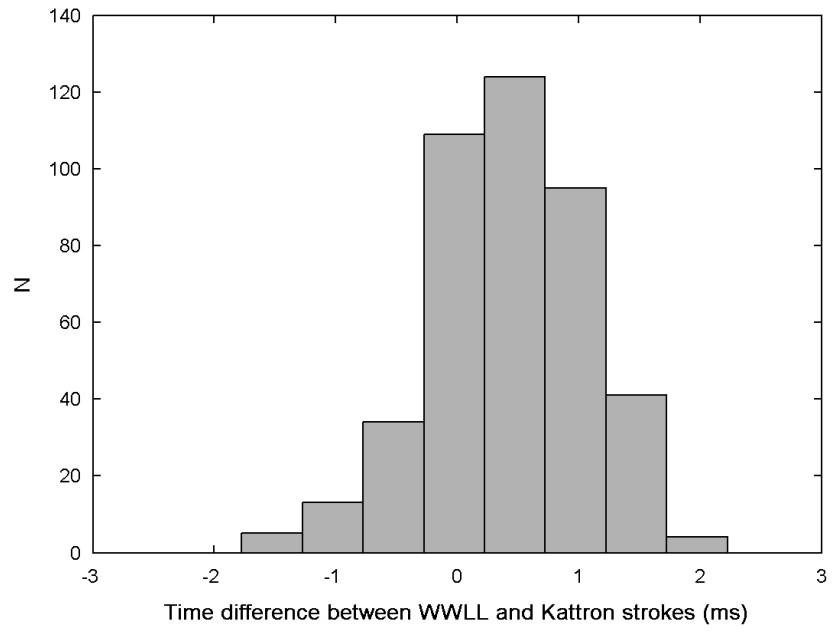

Fig. 3. Time differences between matching events detected by the Kattron and WWLL networks.

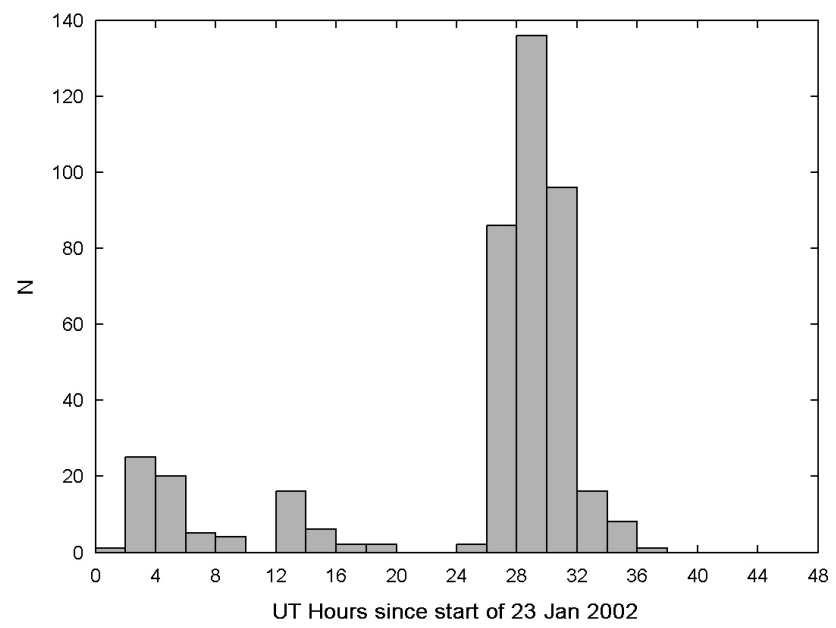

Fig. 4. Diurnal variation of the matching events detected by the Kattron and WWLL networks on 23-24 January 2002.

occurred within $\pm 3 \mathrm{~ms}$ and $50 \mathrm{~km}$ of a lightning event detected by Kattron inside the spatial window shown in Fig. 2, where the WGS-84 Ellipsoid was used to determine the distance difference. Only WWLL events with low residuals $(\leq 50 \mu \mathrm{s})$ were included and these events were limited to locations which had been observed by the receiving stations at Dunedin, Darwin, Perth, and Brisbane, i.e. the 4 receiving stations closest to the spatial window shown in Fig. 2 and listed in the upper part of Table 1. For the time period considered (23-24 January 2002), the WWLL network was limited to 6 stations; the four receiving stations listed above, plus Osaka and Singapore. Due to the high trigger thresholds employed at this time to avoid saturation triggering (as described in Sect. 2.3) the WWLL network produced few lightning locations inside the Kattron high accuracy region, and even fewer which included TOAs from Osaka and Singapore. Thus, we include only locations for the nearest 4 receiving stations, in order to provide a reasonable estimate of 


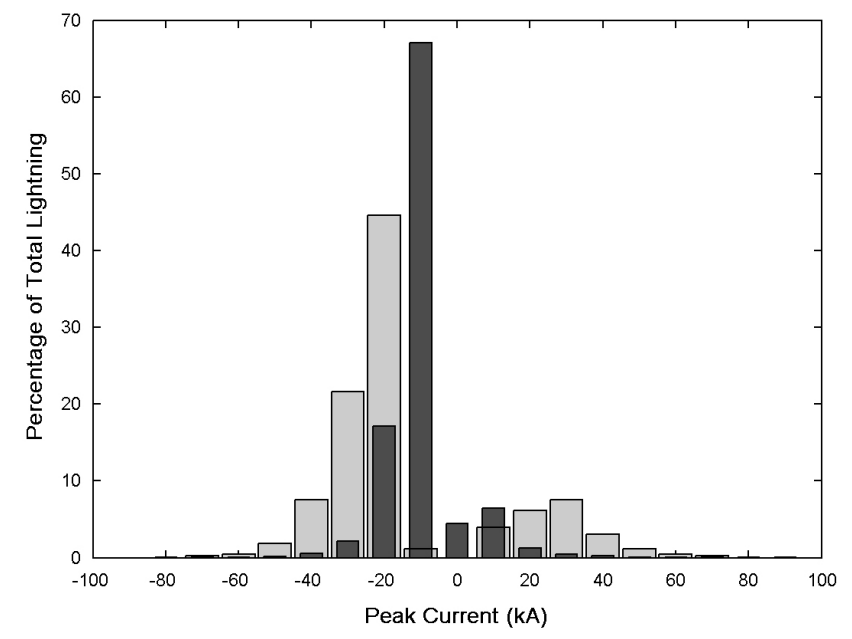

Fig. 5. Distribution of return stroke peak currents determined by the Kattron lightning network. The dark bars show the distribution for all lightning events detected over 23-24 January 2002, while the lighter events show the current distribution for those events which were also detected by the experimental WWLL network.

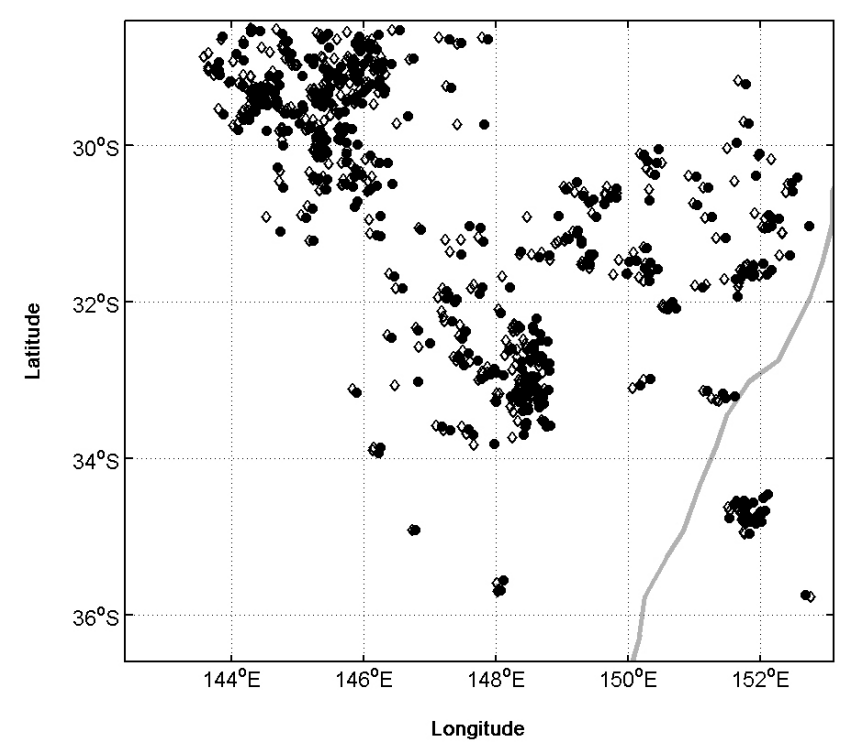

Fig. 6. The positions of the matching lightning events as determined by the Kattron (open diamonds) and WWLL data sets (closed circles). The gray line is part of the east coast of Australia.

the location accuracy of the WWLL network in the "worstcase" situation (with only the minimum of 4 receiving stations involved in each location operation).

Under these restrictions a total of 426 matching lightning events were found. The time differences between the Kattron and WWLL events are shown in Fig. 3. The distribution peaks at $\sim 0.5 \mathrm{~ms}$ as the Kattron data is provided with 1 -ms resolution, while the WWLL lightning data has 1- $\mu \mathrm{s}$ resolution. Note that there are no matching lightning events with time differences greater than $|2 \mathrm{~ms}|$, giving us good confidence that we are correctly identifying coincident light-

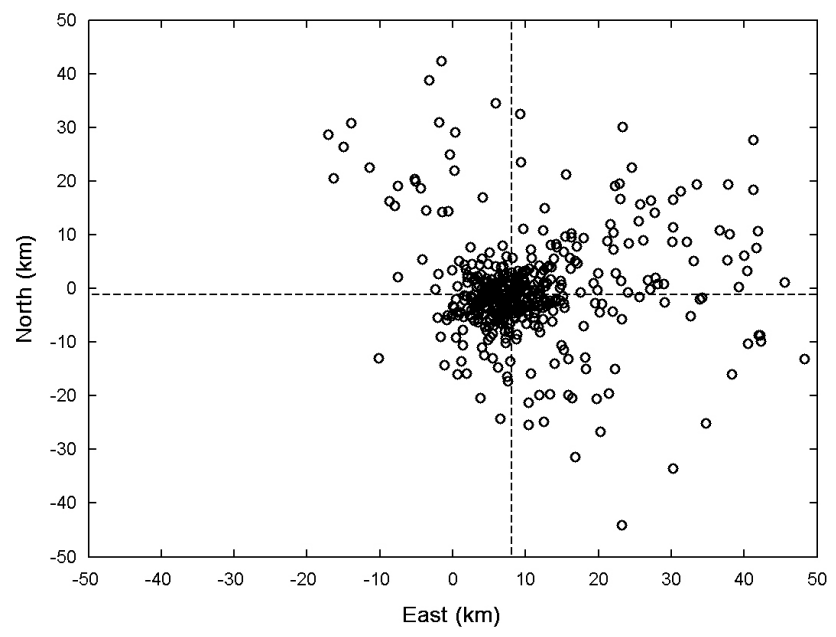

Fig. 7. The east-west and north-south distance differences between the 426 matched lightning event locations (WWLL-Kattron). The dotted lines indicate the median values of these differences.

ning observations. The diurnal variation of the 426 matching events is shown in Fig. 4 over the 2-day period. The majority of the events come from an active period around 02:0009:00 UT ( 10:00-17:00 LT) on 24 January 2002.

The distribution of the Kattron lightning return stroke peak currents is shown as the dark bars in Fig. 5. As expected, the majority of cloud-to-ground (CG) strokes detected by Kattron are of negative polarity and relatively small peak currents, with the mean absolute peak current for all CG strokes detected on these 2 days being $\sim 12 \mathrm{kA}$ and $\sim 8.5 \%$ of the discharges having positive polarity. The distribution of the Kattron determined peak currents for the matching lightning events is shown by the lighter bars in this figure. The mean absolute peak current of the matching events was $\sim 26 \mathrm{kA}$, with $22.5 \%$ of the matched discharges having positive polarity. Clearly, the WWLL network tends to detect lightning discharges with larger return stroke peak currents, which will produce sferics with larger wave amplitudes that are more likely to trigger the receiving stations. We expect that all long-range lightning detection networks will be biased towards high current events producing strong sferics, irrespective of future network developments. It appears that commercial lightning location networks, such as NLDN, currently fail to detect $\sim 50 \%$ of the strokes occurring in a typical flash. It has been suggested that this may be caused by the later strokes in the flash having lower peak currents, too weak to be detected by NLDN sensors (Cummins et al., 1998a).

\subsection{Location differences between the two networks}

The positions of the 426 matching lightning events, as determined by the Kattron (open diamonds) and WWLL data sets (closed circles), are shown in Fig. 6. From the clustering of matching event locations it appears that the WWLL network is successfully determining the location of lightning discharges. However, Fig. 6 suggests that the WWLL 
locations tend to be located eastwards of the Kattron locations. This is confirmed in Fig. 7, which shows the east-west and north-south contributions of the WGS-84 Ellipsoid determined distance differences between the matched locations (WWLL Kattron). The dotted lines indicate the median values of the differences. In the north-south direction the median location difference is $\sim 1 \mathrm{~km}$ southwards, significantly less than the total scatter. However, there appears to be a statistically significant offset in the east-west direction difference, with the median WWLL locations shifted $\sim 8$ km eastwards of the Kattron locations. Thus, the location uncertainty in the WWLL network appears to have two components: the systematic offset described above, plus a random error. This systematic offset may be related to VLF propagation effects, or processing errors, as discussed in Sect. 6.

\subsection{Random errors in the WWLL network}

The random error present in the scatter of the differences in Fig. 7 is described by the mean $(11 \mathrm{~km})$ and standard deviations $(9.4 \mathrm{~km})$ in the location differences after removing the systematic offset. As the error in the lightning locations in the Kattron data should not be correlated with the error in the location deduced in the WWLL network data, we can assume that the random errors in the two data sets are independent. Thus, we can say that,

$\sigma_{m}^{2}=\sigma_{\text {Kattron }}^{2}+\sigma_{\mathrm{WWLL}}^{2}$,

i.e. the variance of the differences between the two datasets is equal to the sum of the variances of the error in each method. From our matched lightning events we have an estimate of $\sigma_{m}=9.4 \mathrm{~km}$, while Fig. 2 indicates that the standard deviations of the errors in the Kattron locations will be no more than $1 \mathrm{~km}$. As the Kattron location error is so very low in the spatial region we have selected, $\sigma_{m}$ should indicate the random location error for the WWLL network in this region with this receiver station configuration (limited to the 4 nearest stations). A comparison of the estimated WWLL location accuracy in this spatial region with the output of the Monte Carlo simulation described in Sect. 3 allows us to determine the appropriate Gaussian timing error for the WWLL network of receiving stations. The modelling suggests that the 4-station WWLL network should have a $\sim 9.5 \mathrm{~km}$ location accuracy when the Gaussian timing error is $\sim 35$, producing the accuracy map shown in Fig. 8. A significant portion of this time error will be due to the use of the trigger time rather than the TOGA at the station. For example, random errors of up to $\pm 20 \mu$ s arise because the trigger time is digitised in approximately $\pm 20 \mu$ s steps, the reciprocal of the sampling frequency (some sound cards sample at $48 \mathrm{kHz}$, some at $50 \mathrm{kHz}$ ). When the TOGA method is implemented, the station timing errors will decrease, as the TOGA time for a sferic can be determined to within a few hundred nanoseconds (Dowden et al., 2002), allowing for an increase in the location accuracies. Hence, the location accuracy estimates shown in this paper will be very conservative for the future WWLL network employing the TOGA technique.

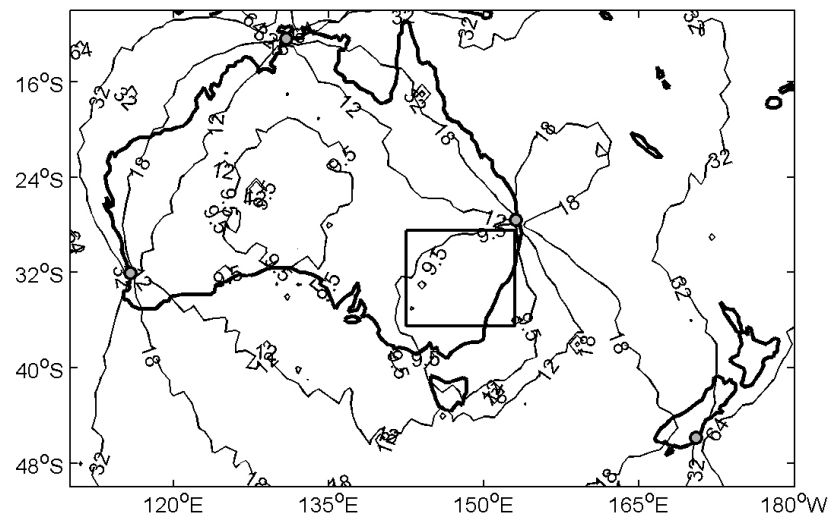

Fig. 8. The estimated location accuracy of the WWLL network when including only the 4 stations nearest to the Kattron high accuracy region in the same format as Figure 1. A $35 \mu$ s timing error is assumed for the network.

\section{Eastwards offset in WWLL locations}

There are two possible explanations for the systematic eastwards offsets in the WWLL locations when compared with those from the Kattron commercial system. The first effect is the anisotropies in VLF propagation in the Earth-ionosphere waveguide. This is considered in the section below. The second is a recently discovered (July 2003) interference problem that affected the receiving station located at Dunedin, New Zealand. In a manner still poorly understood, the Matlab software mapping routines operating on the control station seem to have led to interference in the recording of the GPS-second pulse at the Dunedin receiver site, such that the Dunedin station could sometimes give somewhat earlier trigger times than expected. Such an effect would lead to an average eastwards shift in the locations of events using Dunedin trigger times. This has been corrected, and will not affect the future operation of the network. However, we also need to consider the influence of VLF propagation to determine whether this might play a significant role in location accuracy for the global network of stations now employed in the WWLL system.

\subsection{VLF propagation in long-range lightning networks}

In the current (experimental) WWLL network operation, sferics are assumed to travel from the discharge point to the receiving station at a fixed group velocity $v_{g}=0.9922 c$, irrespective of the time of day or propagation path. It is well known that the group velocity for VLF propagation is dependent upon the wave frequency, ground conductivity and ionospheric parameters along the propagation path, which in the later case will vary strongly from day to night. The fixed group velocity was selected as at $13 \mathrm{kHz}$, near the centre of the received sferic spectrum. The group velocity of the first order mode is rather similar for both day and night paths (Watt, 1967; Dowden et al., 2002). None the less, variation in VLF propagation will be one source of random 


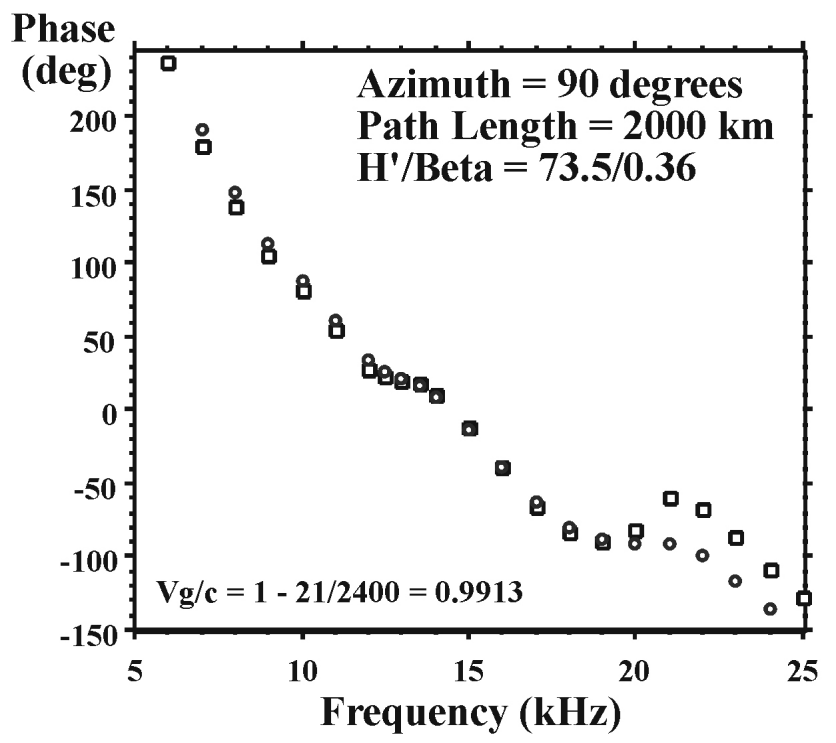

Fig. 9. Variation in the calculated phase at a receiver $2 \mathrm{Mm}$ from the source with frequency, with propagation in the direction west to east. The squares show results using a ground conductivity for a sea water propagation path, while circles are for low conductivity Earth (10-3 S/m), all shifted by $40^{\circ}$, to allow for ready comparison of slopes. The fitted line is used to determine the group velocity as a fraction of the speed of light.

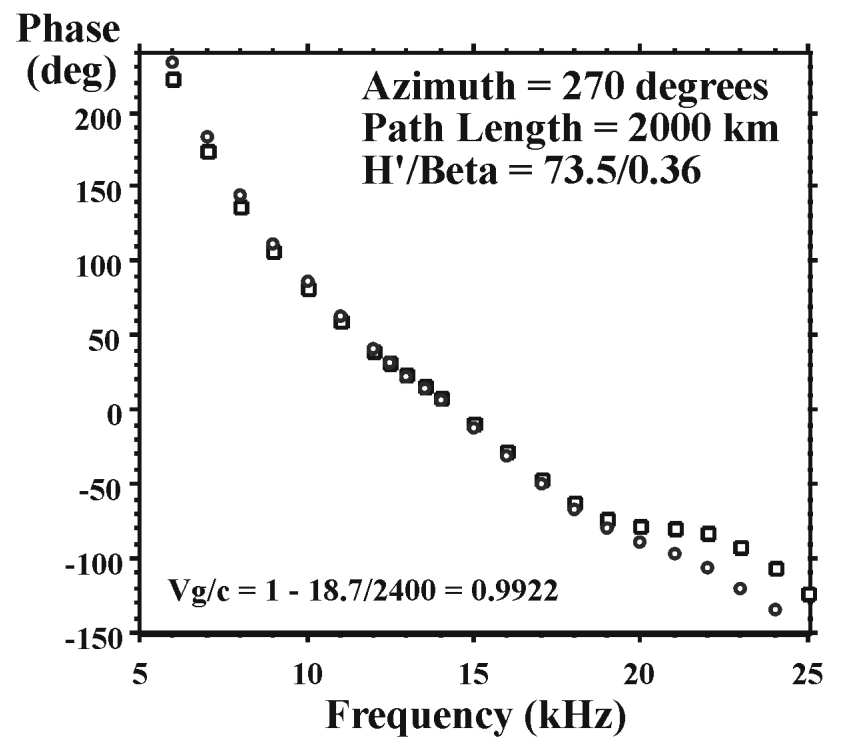

Fig. 10. As Fig. 9 but for propagation in the direction east to west.

errors (as described in Sect. 5.3), and may also lead to systematic offsets. The geomagnetic field leads to an east-west anisotropy in VLF propagation, which is the likely cause of a westward shift in lightning positions observed by an experimental US VLF lightning location network (Morales et al., 2003). In addition, there are also differences in signal attenuation between the east to west and west to east propagation, which will impact detection efficiencies. For example, measurements of $10.2 \mathrm{kHz}$ Omega navigation transmis- sions indicated an attenuation of $2.1 \pm 0.3 \mathrm{~dB} / \mathrm{Mm}$ for west to east, and 2.60.3 dB/Mm for east to west propagation (Nickolaenko, 1995).

\subsection{Group velocity in VLF propagation}

We wish to consider whether the propagation velocity of the lightning in the Earth-ionosphere waveguide might vary enough to lead to the observed systematic offset. At $t=0$, all frequencies at the transmitter are in phase, at least within a range $\Delta \omega$ about the transmitter frequency. Downstream at the receiver, at $t=0$, the frequencies at the top of this band, will typically be more phase delayed than the frequencies at the bottom of this band because there will typically be more wavelengths for the high frequencies along the path than for the low frequencies. This rate of change of phase with frequency, $d \phi / d \omega$, at the receiver at $t=0$, can be measured, or calculated using a waveguide propagation program such as ModeFinder. ModeFinder is a numerical propagation code developed by the United States Naval Ocean Systems Center (NOSC) which assumes a homogeneous ionosphere and ground, including the effects of a spherical Earth (Morfitt and Shellman, 1976). The resulting phase difference at the receiver over the band, $\Delta \omega$, will thus be $\Delta \omega(d \phi / d \omega)$ at $t=0$.

If $t_{g}$ is the group travel time from the transmitter to the receiver, then after tg seconds, the high frequency phase will have advanced by $\Delta \omega t_{g}$ with respect to the low frequency phase, and as the "pulse" which was at the transmitter at $t=0$ will now have arrived at the receiver, all the frequencies over the band $\Delta \omega$ must now be in phase. Hence,

$\Delta \omega t_{g}=\Delta \omega(d \phi / d \omega) \quad$ i.e. $\quad t_{g}=\frac{d \phi}{d \omega}$.

Thus, by measuring $d \phi / d \omega$ for a lightning flash at the receiver, the time of group arrival can be measured, as is discussed further in Dowden et al. (2002). Alternatively, as is done here, the group travel time, $t_{g}$, can be found by calculating the phase, $\phi$, at the receiver as a function of transmitter frequency, $\omega$, using ModeFinder and so $t_{g}=d \phi / d \omega$ can be found for a variety of conditions. Thus, the dependence of $t_{g}$, and hence the group velocity in the Earth-ionosphere waveguide, can be found as a function of the direction of propagation direction, ground conductivity, and the state of the D-region ionization levels.

\subsection{Results of group velocity calculations}

Examples of these calculations are shown in Figs. 9 and 10, taking a path length of $2 \mathrm{Mm}$, roughly representative of $\mathrm{S}$. E. Australia to Dunedin or Perth. The ionosphere used for these calculations was appropriate for a solar zenith angle of $60^{\circ}\left(30^{\circ}\right.$ above the horizon), i.e. when lightning activity was high on these days. West to east propagation (azimuth $90^{\circ}$ ) is shown in Fig. 9 for comparison with east to west propagation (azimuth $270^{\circ}$ ) in Fig. 10. Because the group velocity is close to the speed of light, $c$, ModeFinder calculates (for convenience), the phase difference between the actual propagation and the speed of light propagation. It is this phase 
difference which is shown in the figures. Hence, the $d \phi / d \omega$ from the graphs gives values for the modifications from the speed of light travel time and velocity. Each figure shows data points for two different ground conditions. A ground conductivity close to that of sea water $(4 \mathrm{~S} / \mathrm{m}$, which will predominate for the eastward propagation to NZ) is shown as squares, while the ground conductivity similar to the poorest conducting parts of Western Australia $(0.001 \mathrm{~S} / \mathrm{m})$ is shown as circles.

From the figures it can be seen that even over a wide range of ground conductivities, there is little effect on the group travel times or velocities. In addition, the difference in group velocities between the two propagation directions is only $\sim 0.1 \%$ ( $v_{g} / c$ of 0.9913 c.f. 0.9922$)$, which will not create any significant systematic position errors. Additional calculations undertaken with ionospheric parameters changed to $H^{\prime}=70 \mathrm{~km}, \beta=0.45 \mathrm{~km}-1$, appropriate to near overhead Sun, near solar maximum, (Thomson, 1993) had a negligible effect on the group delays from those seen in the figures.

Finally, we considered the effects of a C7.1 solar flare which started at 03:25 UT on 24 January 2002, peaked at 04:39 UT and lasted until 07:06 UT, i.e. during the time of maximum lightning activity over the 2 days for which we have purchased Kattron data. It was found from the matching lightning events that the locations during the solar flare period were no clearly more affected by the eastwards shift than those outside of this time.

\subsection{Implications}

It therefore appears that anisotropies in VLF propagation in the Earth-ionosphere waveguide will not lead to significant systematic eastward offsets in the WWLL locations. We suggest that the interference in Dunedin-recorded times is likely to explain the offset. It will be necessary to test this suggestion using more modern observations (post July 2003). However, as the WWLL network is now very different from that which existed in January 2002, confirmation that there is no longer a systematic location offset in WWLL data will be left for a consideration of the updated WWLL network, making use of the TOGA technique. It should be noted that WWLL lightning locations, which included Dunedin TOA observations, are somewhat suspect, and are likely to suffer from systematic offsets towards Dunedin (mean of $\sim 8 \mathrm{~km}$ ). In the specific case considered in this paper, that offset is almost entirely eastwards. For more northern locations the Dunedin anomaly may lead to a similarly significant southwards component in data collected before July 2003.

\section{Estimate of global WWLL location accuracy}

The analysis above has provided us with an estimate for the "worst-case" WWLL lightning location accuracies in Australasia, where only the 4 Australasian receiving stations are involved in the location process, as well as an estimate for the timing error for the WWLL network of receiving stations.
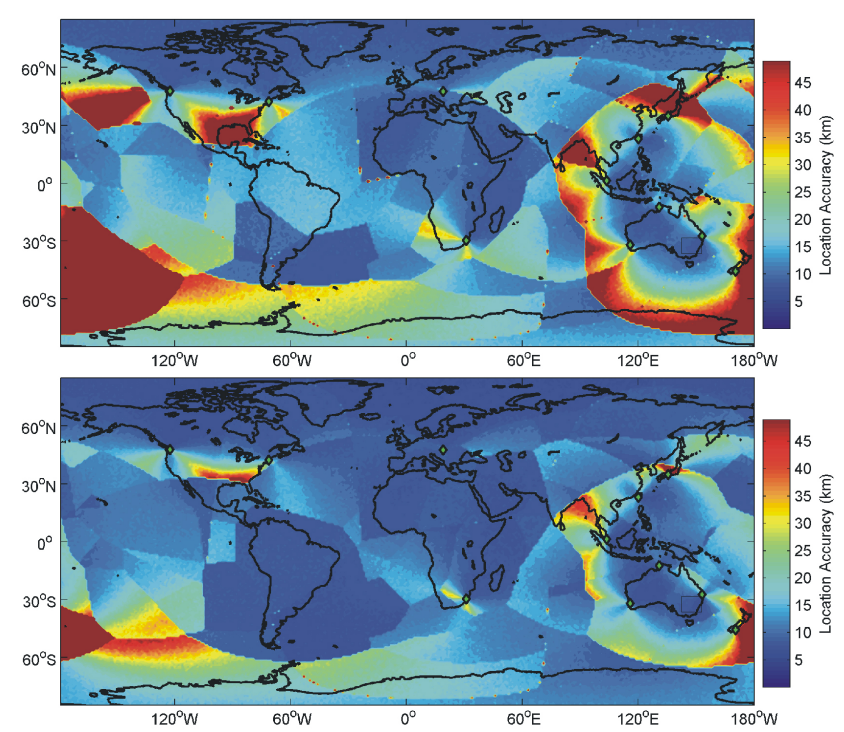

Fig. 11. An estimate of the global location accuracy of the 11 receiving station WWLL network listed in Table 1, assuming a $35 \mu \mathrm{s}$ timing error. The upper panel shows location accuracies assuming that only the minimum 4 receiving stations report a lightning event, while the lower panel shows the same situation for 5 receiving stations.

Using this timing error we can estimate the global lightning location accuracies for the entire network of 11 receiving stations listed in Table 1, assuming that only the minimum number of receiving stations (taken to be the 4 nearest stations) is involved in each location finding process. We also assume that only random errors are present in the network and any systematic offsets have been corrected for. The global lightning location accuracy is shown in the top panel of Fig. 11. The global location accuracy for this network ranges over $7.5-110 \mathrm{~km}$, with the global median being $15 \mathrm{~km}$, and the global mean $30 \mathrm{~km}$. The strong discontinuities seen in the figure are due to the requirement that only the 4 nearest stations are involved in the lightning location process, leading to artificially poor accuracy in the Western Pacific area where the receiving station density is higher. In order to estimate the significance of this effect, we have also produced a map of the global location accuracies, assuming that the 5 nearest stations take place in locating each lightning flash, as shown in the lower panel of Fig. 11. This leads to improvements in the location accuracies for many of the red regions seen in the upper panel. While the choice of 4 stations is somewhat artificial, an analysis of the lightning locations produced by the 11-station network in April-May 2003 suggests that around half of all events are observed by 4 stations, and $25 \%$ by 5 stations, with the latter case being more common in South East Asia and Central Africa. Assuming the 11-station lightning network may be reasonably represented with a timing error of $35 \mu \mathrm{s}$, the location accuracy map will generally lie somewhere between the upper and lower panel of Fig. 11, depending on the spatial location. None the less, we caution that the global location accuracies shown in Fig. 11 are based 


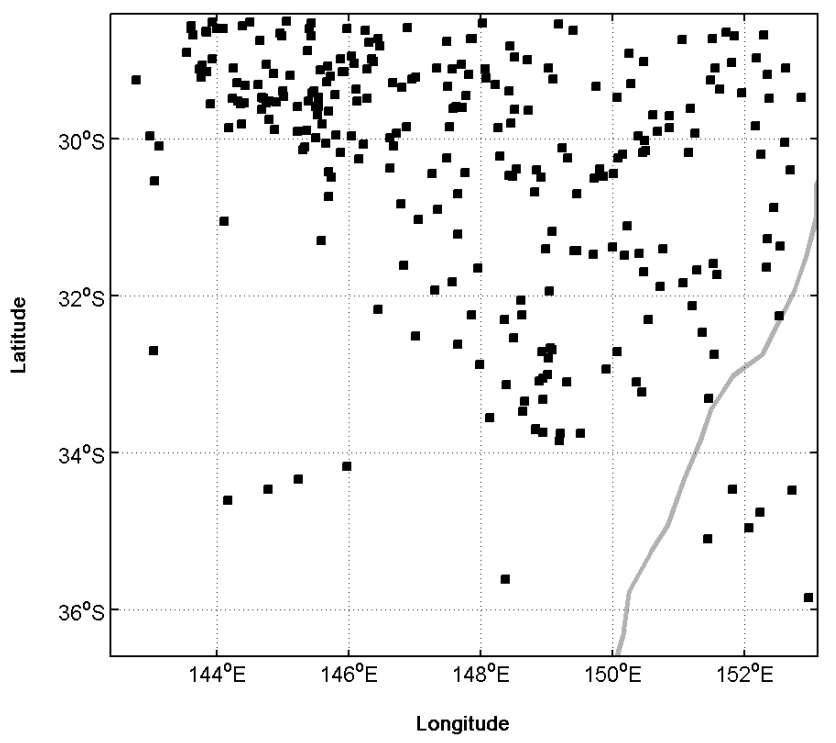

Fig. 12. The positions of the unmatched locations from the WWLL data set (black squares), in the same format as Fig. 6 .

upon on extrapolation from a small region in Australia. Future studies need to be undertaken using independent lightning location data for locations elsewhere in the world, as well as to confirm the improvements in timing errors from the use of TOGAs rather than trigger times in the location process.

\section{Discussion}

In the 2 days over which the comparison between the experimental WWLL network and Kattron data was conducted, the Kattron network reported 30402 lightning locations inside the spatial window selected, while the experimental WWLL network reported 698 lightning locations, of which 426 events were found to match. This very low percentage $(\sim 1 \%)$ is, however, not indicative of the true detection efficiency of the planned WWLL network, and reflects a period when the triggering thresholds were set high to avoid network saturation. The aim of the operational WWLL network is a $50 \%$ flash detection efficiency. While this has not been achieved to date, it is estimated that the flash detection efficiency for April-May 2003 was $\sim 13 \%$ in the Asian/Australian region where the station density is the highest (Rodger and Dowden, 2003).

In addition to the 426 matching events found in the two data sets, there were also 272 WWLL events which did not match Kattron lightning locations. As noted above, the Kattron network should have at least an $80 \%$ detection efficiency for cloud-to-ground discharges inside the spatial region selected in our study. On this basis it seems unlikely that Kattron could have missed so many cloud-to-ground discharges which were strong enough for the WWLL to detect. However, the spatial distribution of these "un-matched" events is very similar to those of the matched events (Fig. 12), as would be expected for events produced by discharges occur- ring inside active thunderstorms. At VLF frequencies the return stroke of cloud-to-ground discharges is the dominant source of received sferics (Pierce, 1977), and thus should strongly dominate the lightning observations, even though there are $\sim 3.5$ times more intracloud (IC) lightning flashes (sometimes simply termed "cloud flashes") than cloud-toground (CG) lightning flashes (Mackerras et al., 1998). None the less, at $10 \mathrm{kHz}$ the radiation from IC flashes is $\sim 10 \%$ of those of CG flashes (Brook and Ogawa, 1977) and thus IC lightning may be detectable by VLF systems. An experimental VLF lightning location network operated in the US detected $\sim 60 \%$ of CG discharges and $\sim 10 \%$ of IC discharges (Morales et al., 2003), and, therefore, some of the unmatched WWLL events may have been produced by IC discharges rejected by the Kattron lightning location network. In addition, it has been found that some intense CG discharges are rejected by the LPATS-sensors employed by NLDN, as the received waveform does not conform to the standard shape used by the NLDN processing algorithm (Personal communication, Robert Holzworth, 2003). This may also be a source of potential intense lightning discharges which would be recorded by the WWLL but unrecorded by Kattron. Wideband recordings undertaken during WWLL observations might allow for the identification of IC and CG events, or at least the confirmation that some form of discharges did take place at a given time.

Another possible source of lightning location data by which comparisons could be made with the WWLL network locations is from Earth-orbiting satellites. The Lightning Imaging Sensor (LIS) aboard the Tropical Rainfall Measuring Mission satellite detects lightning optically by observing the neutral oxygen line at $777.4 \mathrm{~nm}$ (Orville, 1995). Comparisons of LIS, NLDN, and VHF radar lightning observations found that the LIS tends to detect cloud to ground (CG) discharges towards the end of the discharge process, probably the late stage in-cloud components of the CG discharge, occurring in the upper parts of the thundercloud. Differences of $\sim 1 \mathrm{~s}$ were possible between the NLDN and LIS detections (Thomas et al., 2000). Such timing differences will make it difficult to make direct comparisons between the WWLL locations and those observed by satellite. None the less, this may allow for some matching lightning events to be found in regions of the Earth where no other lightning detection experiments operate.

\section{Conclusions}

An experimental VLF WorldWide Lightning Location (WWLL) network is being developed through collaborations with research institutions across the globe. The aim of the WWLL is to provide real-time locations of cloud-toground lightning discharges occurring throughout the globe. This network has expanded from a limited number of stations in the Western Pacific to its current state of 11 stations which cover most longitude sectors, with additional stations planned in the near future. As part of the initial testing phase 
of the WWLL the network has operated in a simple mode sending the station trigger times into a central processing point, thereby providing the sferic Time of Group Arrival (TOGA). During this initial stage, a significant quantity of lightning location data has been collected, some of which is being applied to research questions. In this paper the location accuracy of the pre-TOGA WWLL network has been characterised, particularly focusing on the early stages of the network structure where stations were limited to the Western Pacific (pre-March 2003).

Estimates of the location accuracy have been found by comparison with commercial lightning location data purchased from an Australian network, Kattron. It was found that there were 426 matched lightning events over two days in January 2002 in a region where the Kattron location error is modelled as being $<1 \mathrm{~km}$. These matched events corresponded to large Kattron determined lightning return stroke peak currents (mean absolute peak current of $\sim 26 \mathrm{kA}$ compared with $\sim 12 \mathrm{kA}$ for all Kattron events). The WWLL locations were found to have both a random and a systematic offset from the Kattron-determined locations, with WWLL locations systematically displaced by $\sim 8 \mathrm{~km}$ eastwards. Modelling suggests this is not due to anisotropies in VLF propagation in the Earth-ionosphere waveguide, but may be explained by a fault in one of the Australasian receiving stations which has since been rectified.

The random errors in the differences are described by a mean of $11 \mathrm{~km}$ and a standard deviation of $9.4 \mathrm{~km}$. A comparison of this WWLL location accuracy in the spatial region selected with the output of a Monte Carlo simulation allows us to determine the appropriate Gaussian timing error for the WWLL network of receiving stations $(\sim 35 \mu \mathrm{s})$, and hence simulate the location errors for the existing 11station network. The "worst-case" global location accuracy for the existing network ranges spatially from $7.5-110 \mathrm{~km}$, with the global median being $15 \mathrm{~km}$, and the global mean $30 \mathrm{~km}$. When the TOGA method is implemented, the station timing errors will decrease, allowing for an increase in the location accuracies. Hence the location accuracy estimates determined in this paper will be very conservative for the future WWLL network employing the TOGA technique.

Acknowledgements. C. J. Rodger would also like to thank J. Speight of Dunedin for his support. C. J. Rodger was supported by the New Zealand Marsden Research Fund contract 02-UOO106, while the Australasian network activities were supported by the Australian Research Council contract LP 0219331. We thank the University of Otago, Dunedin, New Zealand; Northern Territory University, Darwin, Australia; Murdoch University, Perth, Australia; Griffith University, Brisbane, Australia; Osaka University, Japan; National University of Singapore, Singapore; National Cheng Kung University, Tainan, Taiwan; University of Washington, Seattle, USA; Massachusetts Institute of Technology, USA; Etvs University, Budapest, Hungary; and the University of Natal, Durban, RSA for housing our VLF lightning acquisition receivers.

Topical editor O. Boucher thanks A. P. Nickolaenko for his help in evaluating this paper.

\section{References}

Brook, M. and Ogawa, T.: The cloud discharge, in lightning, vol. 1, edited by Golde, R. H. Academic Press, New York, 191-230, 1977.

Brundell, J. B., Rodger, C. J., and Dowden, R. L.: Validation of single station lightning location technique, Radio Sci., 37(4), 10.1029/2001RS002477, 2002.

Chronis, T. G., and Anagnostou, E. N.: Error analysis for a longrange lightning monitoring network of ground-based receivers in Europe, J. Geophys. Res., 108(24), 10.1029/2003JD003776, 2003.

Crombie, D. D.: Periodic fading of VLF signals received over long paths during sunrise and sunset. Journal of Research National Bureau of Standards, Radio Science, 68D, 27-34, 1964.

Cummer, S. A., Inan, U. S., and Bell, T. F.: Ionospheric D region remote sensing using VLF radio atmospherics, Radio Sci. 33, 1781-1792, 1998.

Cummins, K. L., and Murphy, M. J.: Overview of lightning detection in the VLF, LF, and VHF frequency ranges, 2000 International Lightning Detection Conference, Tucson, Arizona, 1-10, 2000.

Cummins, K. L., Murphy,M. J., Bardo, E. A., Hiscox, W. L., Pyle, R. B., and Pifer, A. E.: A combined TOA/MDF technology upgrade of the U.S, National Lightning Detection Network, J. Geophys. Res, 103, 9035-9044, 1998a.

Cummins, K. L., Krider, E. P., and Malone,M. D.: The U.S. national lightning detection network and applications of cloud-to-ground lightning data by electric power utilities, IEEE Trans. Electromagn. Comp., 40(4), 465-480, 1998 b.

Dowden, R. L., and Rodger, C. J.: True global mapping of lightning using widely spaced VLF receivers on the ground, 27th General Assembly of URSI CD-ROM, August 2002.

Dowden, R. L., Brundell, J. B., and Rodger, C. J.: VLF lightning location by time of group arrival (TOGA) at multiple sites, J. Atmos. Sol. Terr. Phys., 64, 817-830, 2002.

Hamid, E. F., Kawasaki, Z.-I., and Mardiana, R.: Impact of the 1997-1998 El niño event on lightning activity over Indonesia, Geophys. Res. Lett., 28, 147-150, 2001.

Jourdain, L., and Hauglustaine, D. A.: The global distribution of lightning NOx simulated on- line in a general circulation model, Phys. Chem. Earth Pt. C-Solar-Terr. Planet. Sci, 26, 585-591, 2001.

Lee, A. C. L.: An experimental study of the remote location of lightning flashes using a VLF arrival time difference technique, Q. J. Royal Met. Soc., 112, 203-229, 1986a.

Lee, A. C. L.: An operational system for the remote location of lightning flashes using a VLF arrival time difference technique, J. Atmos. and Oceanic Tech., 3, 630-642, 1986b.

Lee, A. C. L.: Ground truth confirmation and theoretical limits of an experimental VLF arrival time difference lightning flash locating system, Q. J. Royal Met. Soc., 115, 1147-1166, 1989.

Lyons, W. A., Nelson, T. E., Williams, E. R., Cramer, J. A., and Turner, T. R.: Enhanced positive cloud-to-ground lightning in thunderstorms ingesting smoke from fires, Science, 282, 77-80, 1998.

Mackerras, D., Darveniza, M., Orville, R. E., Williams, E. R., and Goodman, S. J.: Global lightning: Total, cloud and ground flash estimates. J. Geophys. Res., 103, 19791-19809, 1998.

Magono, C.: Thunderstorms, Elsevier Sci., Amsterdam, 1980.

Morales, C. A., Weiman, J. A., Anagnostou, E. N., Goodman, S., and Williams, E.: Continuous long- range thunderstorm 
monitoring by a VLF receiver network: Location error analysis and cloud-to-ground and intra-cloud detection efficiency, J. Atmos. Ocean. Tech., 2004. Available in preprint form from: http://sifnos.engr.uconn.edu/ manos/mwa02.pdf.

Morfitt, D. G. and Shellman, C. H.: MODESRCH: An improved computer program for obtaining ELF/VLF/LF propagation data, Tech. Rep. NOSC/TR 141, Nav. Ocean Syst. Cent., San Diego, Calif., 1976. (Available as ADA047508 from Nat. Tech. Inf. Serv., Springfield, Va.)

Nickolaenko, A.P.: ELF/VLF propagation measurements in the Atlantic during 1989, J. Atmos. Sol. Terr. Phys., 57, 821-833, 1995.

Orville, R. E.: Lightning detection from ground and space, in handbook of atmospheric electrodynamics; Vol. 1, second edition, edited by H. Volland, pp. 137-149, CRC Press, Boca Raton, Fl., 1995.

Pierce, E. T.: Atmospherics and radio noise, in Lightning, vol. 1, edited by R. H. Golde, pp. 309-350, Academic Press, New York, 1977.

Rafalsky, V. A., Nickolaenko, A. P. Shvets and Hayakawa, M.: Location of lightning discharges from a single station, J. Geophys. ResA. V., 100, 20 829-20 838, 1995.

Rodger, C. J.: Red sprites, upward lightning, and VLF perturbations, Rev.Geophys., 37, 317-336, 1999.

Rodger, C. J. and Dowden, R. L.: Realtime global mapping of lightning using widely spaced VLF receivers, XXIII General Assembly of the International Union of Geodesy and Geophysics, Abstracts Week B, Pg B.193, IUGG, Japan, 2003.
Rodger, C. J. and Clilverd, M. A.: Inner radiation belt electron lifetimes due to whistler-induced electron precipitation (WEP) driven losses, Geophys. Res. Lett., 29(19), 10.1029/2002GL015795, 2002.

Schlegel, K., Diendorfer, G., Thern, S., and Schmidt, M.: Thunderstorms, lightning and solar activity - Middle Europe, J. Atmos. Sol.-Terr. Phys., 63, 1705-1713, 2001.

Su, H. T., Hsu, R. R., Chen, A. B., Wang, Y. C., Hsiao, W. S., Lai, W. C., Lee, L. C., Sato, M., and Fukunishi, H.: Gigantic jets between a thundercloud and the ionosphere, Nature, 423, 974976, 2003.

Thomas, R. J., Krehbiel, P. R., Rison, W., Hamlin, T., Boccipio, D. J., Goodman, S. J., and Christian, H. J.: Comparison of ground-based 3-dimensional lightning mapping observations with satellite-based LIS observations in Oklahoma, Geophys. Res. Lett., 27, 1703-1706, 2000.

Thomson, N. R.: Experimental daytime VLF ionospheric parameters, J. Atmos. Terr. Phys., 55, 173-184, 1993.

Uman, M. A.: The Lightning Discharge, Int. Geophys. Ser., Vol. 39, Academic Press, San Diego, Calif., 1987.

Watt, A. D.: VLF radio engineering, International monographs in electromagnetic waves, Vol. 14, Pergamon, Oxford, U.K., 1967.

Williams, E. R.: The Schumann Resonance: A global tropical thermometer, Science, 256, 1184-1187, 1992.

Yair, Y.: A tribute to the astronauts of STS-107, who gave their lives in the pursuit of scientific research from space, J. Atmos. Sol. Terr. Phys., 65(5), 495, 2003. 